\title{
Hormonal mechanisms in the onset of puberty
}

\author{
RONALD S. SWERDLOFF* \\ M.D. \\ William D. ODELL \\ M.D., Ph.D.
}

Division of Endocrinology, Harbor General Hospital Campus, U.C.L.A. School of Medicine, U.S.A.

\begin{abstract}
Summary
Sexual maturation is associated with increasing levels of sex steroids. These steroidal events are the result of complex changes that occur at several functional levels including the hypothalamus, pituitary, gonad and adrenal gland. These changes, as outlined in Table 3, are often interrelated.

While considerable progress has been made in our understanding of the hormonal events associated with sexual maturation, many important questions remain unanswered. Further intensive investigation will be required before we have a lucid understanding of the physiological basis of the sequence of hormonal events which occur during the pubertal process.
\end{abstract}

\section{Sexual maturation}

The transformation of a sexually immature child into an adult capable of normal reproductive competence is the result of a complex series of hormonal events. The sequence of development of the many physical changes associated with puberty have been

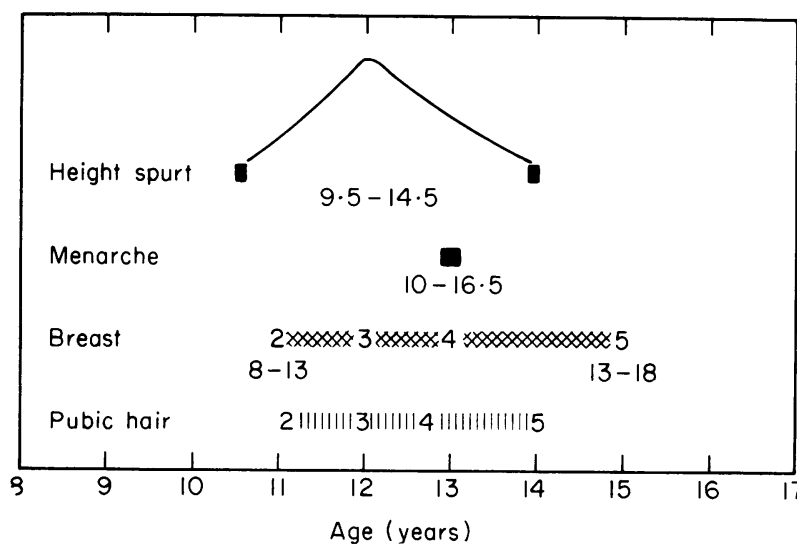

FIG. 1. Sequence of development of physical changes associated with puberty in girls. The numbers $2-5$ refer to the Tanner stages of pubic hair and breast development (with permission from Marshall and Tanner, 1970).

* Recipient of USPHS Career Development Award \#5 KO4 HD 70436-02.

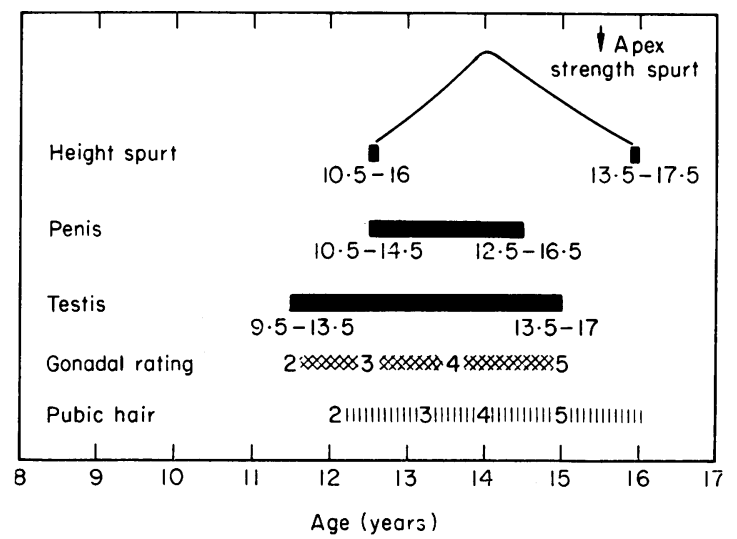

FIG. 2. Sequence of development of physical changes associated with puberty in boys. The numbers 2-5 refer to the Tanner stages of pubic hair and genital development (with permission from Marshall and Tanner, 1970).

carefully documented by Marshall and Tanner (1969, 1970). The physical changes which occur over a time span of several years have been subdivided into several stages for simpler discussion of chronology, relationship to hormonal changes and diagnosis of abnormal maturational development. The widely used classification system of Marshall and Tanner $(1969,1970)$ actually represents two classifications based on separate but interrelated events, e.g. pubic hair and genital development in the male. Figures 1 and 2 represent the chronology of these stages in boys and girls during the past two decades in England. Efforts have been made by several groups to develop a composite staging system to allow for easier correlation with hormonal events (e.g. Winter and Faiman, 1972a). Similar classification systems used in our clinics are presented in Table 1 and 2. The ages of children in whom these pubertal stages are observed differ depending on the geographical and nutritional environment of the children. The latter factor has been proposed as the explanation for the trend toward the earlier development of menarche (Tanner, 1962; Frisch, 1972) observed over the past century. 
TABLE 1. Composite stages of sexual development in males

\begin{tabular}{cc}
\hline Stage & Description \\
\hline P-1 & $\begin{array}{c}\text { Preadolescent; largest testes diameter }<2 \cdot 4 \\
\text { cm; no pubic hair or penile enlargement }\end{array}$ \\
P-2 & $\begin{array}{c}\text { Sparse pubic hair, mainly at base of penis; } \\
\text { testis diameter } 2 \cdot 4-3 \cdot 2 \mathrm{~cm} \text {; scrotal skin } \\
\text { reddened; little penile enlargement } \\
\text { Pubic hair darker, coarser, but limited in dis- } \\
\text { tribution; early penis enlargement; sparse } \\
\text { axillary hair; testes diameter 3.3-4.0 cm; } \\
\text { scrotal skin darker } \\
\text { Adult pubic hair; moderate axillary hair; } \\
\text { testis diameter } 4 \cdot 1-4 \cdot 5 \mathrm{~cm}\end{array}$ \\
P-4 & $\begin{array}{c}\text { Adult secondary characteristics; testis dia- } \\
\text { meter greater than } 4 \cdot 5 \mathrm{~cm}\end{array}$ \\
\hline
\end{tabular}

Adapted from Marshall and Tanner (1970) and Winter and Faiman (1972a).

TABLE 2. Composite stages of sexual development in females

\begin{tabular}{cl}
\hline Stage & \multicolumn{1}{c}{ Description } \\
\hline P-1 & Preadolescent \\
P-2 & Breast budding; early labial hair growth \\
P-3 & $\begin{array}{c}\text { Increased breast size with palpable glandular } \\
\text { tissue; no separating of breast contours; } \\
\text { moderately dark coarser labial hair over } \\
\\
\text { mons pubis }\end{array}$ \\
P-4 & $\begin{array}{l}\text { Further enlargement of breasts with projec- } \\
\text { tion of areola above breast plane; lateral } \\
\text { spread of pubic hair }\end{array}$ \\
& Adult breast size and pubic hair distribution \\
\hline
\end{tabular}

Adapted from Marshall and Tanner (1969).

\section{Hormonal events in puberty}

With the exception of gonadal size, most of the visible changes associated with puberty in both sexes are due to increased production of steroid hormones. These hormones are secreted directly by the gonads and adrenals or are converted from precursor steroids secreted by the adrenals. In the male, pubic, axillary and facial hair, phallic enlargement, change in muscle mass and epiphyseal closure all result from increasing concentrations of androgens. These androgens are predominantly produced by the testes, but a small contribution is due to the direct secretion of weak androgens and androgen precursors from the adrenal glands. In the female, breast development, female fat distribution, vaginal and uterine development, linear growth velocity and skeletal maturation are the result of increasing oestrogen secretion by the ovary. The mechanism by which increased production of adrenal androgens (adrenarche) occurs at puberty is incompletely understood. The gonads are under the control of the pituitary gonadotrophic hormones (LH, FSH and possibly prolactin). Secretion of $\mathrm{LH}$ and FSH depends on the stimulatory effects of the hypothalamic releasing hormone, GnRH (Schally, Kastin and Arimura, 1971). GnRH secretion is regulated by hypothalamic monoamines such as norepinephrine, dopamine and serotonin (Kamberi, Mical and Porter, 1971). Higher CNS structures undoubtedly influence the production of the latter substances.

Both hypothalamic and pituitary function are influenced by the gonads. In the male, testosterone, dihydrotestosterone, oestradiol and perhaps other gonadal substances act via negative feedback to inhibit the secretion of LH and FSH (Swerdloff et al., 1973; Walsh, Swerdloff and Odell, 1973a, b). It is likely that this negative feedback occurs both at the hypothalamic level (inhibiting the secretion of GnRH) (Smith and Davidson, 1967) and at the pituitary level (Wollessen et al., 1974; Vera, Swerdloff and Odell, 1974) inhibiting the effects of GnRH on LH and FSH secretion. Thus, in a normal adult male, castration results in increased secretion of $\mathrm{LH}$ and FSH owing to the absence of the inhibitory effects of gonadal steroids. Treatment of such a person with androgens and/or oestrogens results in a return of these gonadotrophins towards normal. The feedback system for the male is depicted in Fig. 3.

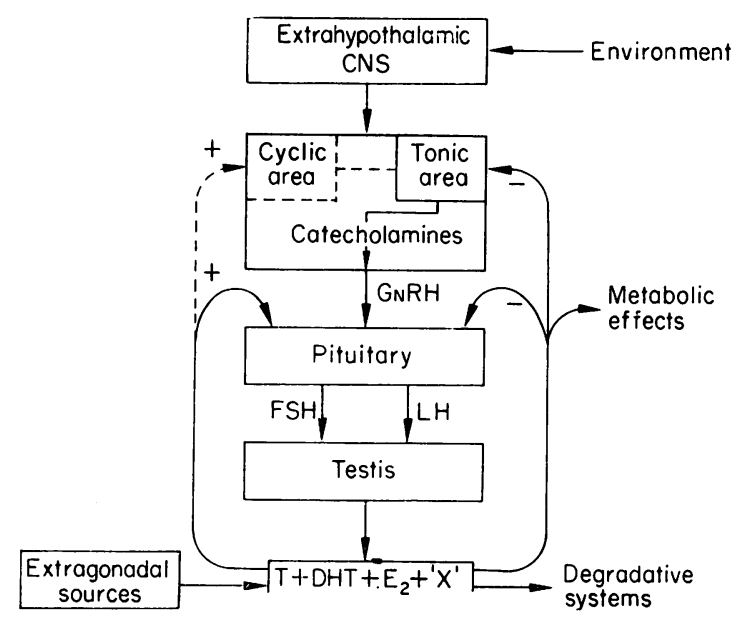

FIG. 3. Hypothalamic-pituitary-gonadal feedback system of the male. The extragonadal sources of androgen referred to include androgens and androgen precursors produced by the adrenal glands. The testis directly secretes testosterone, dehydrotestosterone and oestradiol. Other substances have been postulated to be secreted by the testes which are believed to have an influence on FSH secretion. Such a substance referred to as ' $X$ ' in the diagram has been given various names including 'inhibin'.

In the female (as in the male), a tonic negative feedback system exists and ovarian steroids (oestrogen and progesterone) inhibit LH and FSH secretion 
(Odell and Swerdloff, 1968; Swerdloff and Odell, 1969). This inhibitory influence probably occurs at both hypothalamic and pituitary levels. In addition, the female has a positive feedback system (Fig. 4) by which oestrogens stimulate LH secretion (Swerdloff and Odell, 1969; Yenn, 1971). Progestogens may synergize with oestrogens in this stimulatory action on LH secretion and they may be necessary for stimulation at midcycle (Odell and Swerdloff, 1968; Swerdloff, Jacobs and Odell, 1972a). This stimulatory action of gonadal steroids results in the pre-ovulatory surge of LH and FSH observed at midcycle.

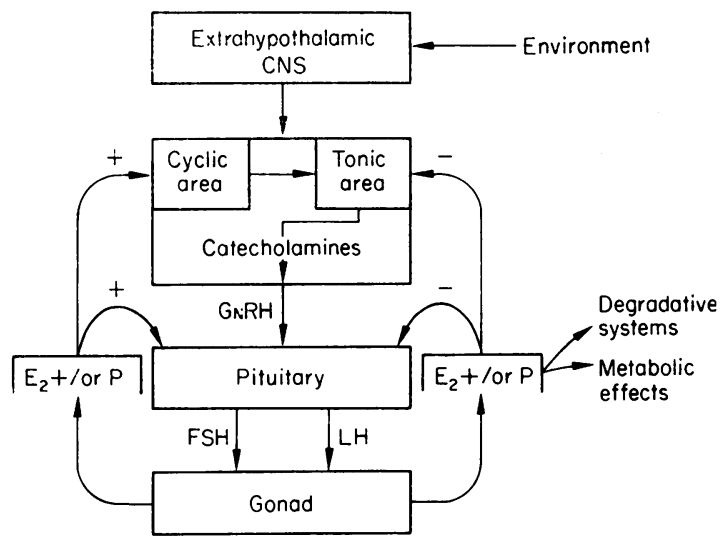

Fig. 4. Hypothalamic-pituitary-gonadal feedback system of the female.

Figure 5 depicts the cyclic changes of serum $\mathbf{L H}$, FSH, oestradiol and progesterone during a normal menstrual cycle (Abraham et al., 1971). The following sequence of events occurs. FSH rises early in the cycle and stimulates growth of the ovarian follicle. The growing follicle secretes increasing amounts of oestradiol (and 17- $\alpha$-hydroxy-progesterone). When the oestradiol concentration reaches a critical level, it triggers release of large quantities of LH and FSH. Ovulation then occurs and a corpus luteum develops. Progesterone concentrations, which begin to rise just before the midcycle LH peak, are markedly increased during the luteal phase. The elevated concentrations of oestradiol and progesterone act via the negative feedback system to inhibit secretion of LH and FSH. Finally, as the function of the corpus luteum diminishes, serum oestradiol and progesterone levels fall and menstruation occurs. This decrease in gonadal steroids is then followed by a rise in serum FSH, thereby initiating another cycle. For complete sexual maturation to occur, this entire system must be functional. The remainder of this paper will deal with the hormonal events that lead to sexual maturation.
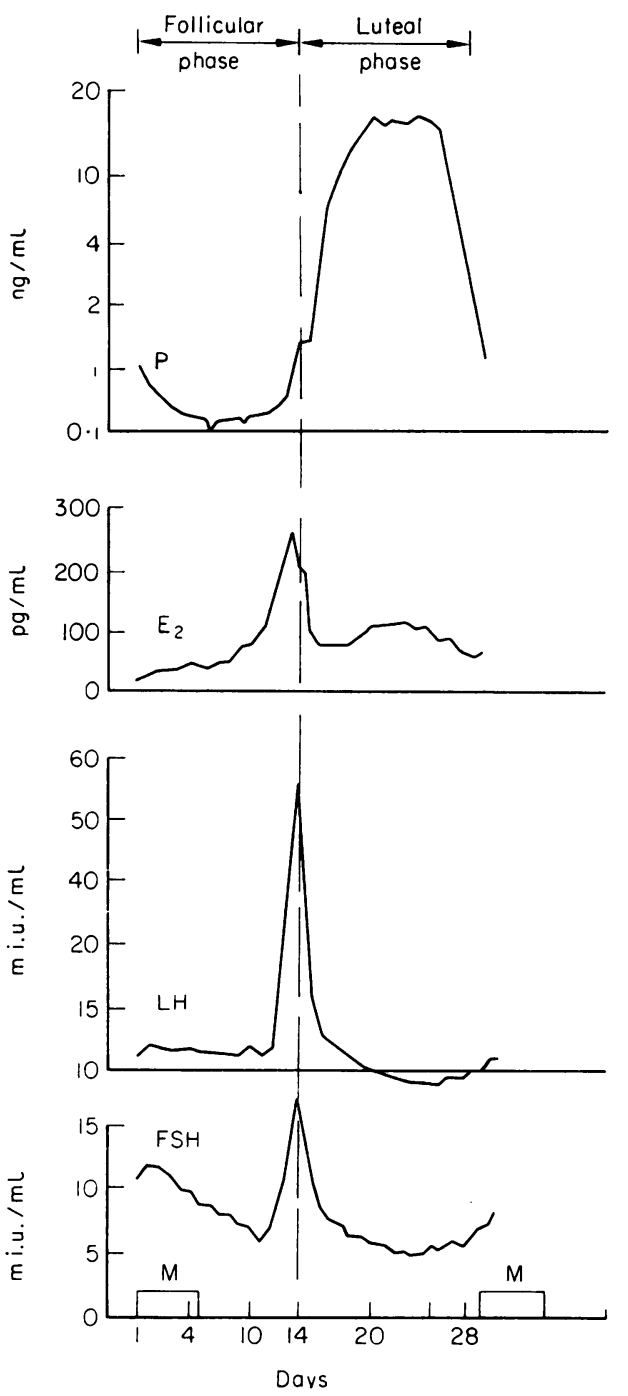

Fig. 5. Daily serum LH, FSH, oestradiol-17B and progesterone concentrations in a normal menstrual cycle (with permission from Abraham et al., 1971).

\section{Gonadotrophins}

Until recently, most physicians believed that the prepubertal child was not able to secrete gonadotrophins. It was believed that puberty was initiated by the onset of LH and FSH secretion. This thesis was proved to be incorrect by the demonstration, using radioimmunassays, that $\mathrm{LH}$ was present in the serum of all children (Odell, Ross and Rayford, 1967). The above finding was confirmed by the same group of investigators using the mouse uterine weight bioassay. They showed that biologically active gonadotrophins were present in the urine of prepubertal children (Rifkind, Kulin and Ross, 1967). 


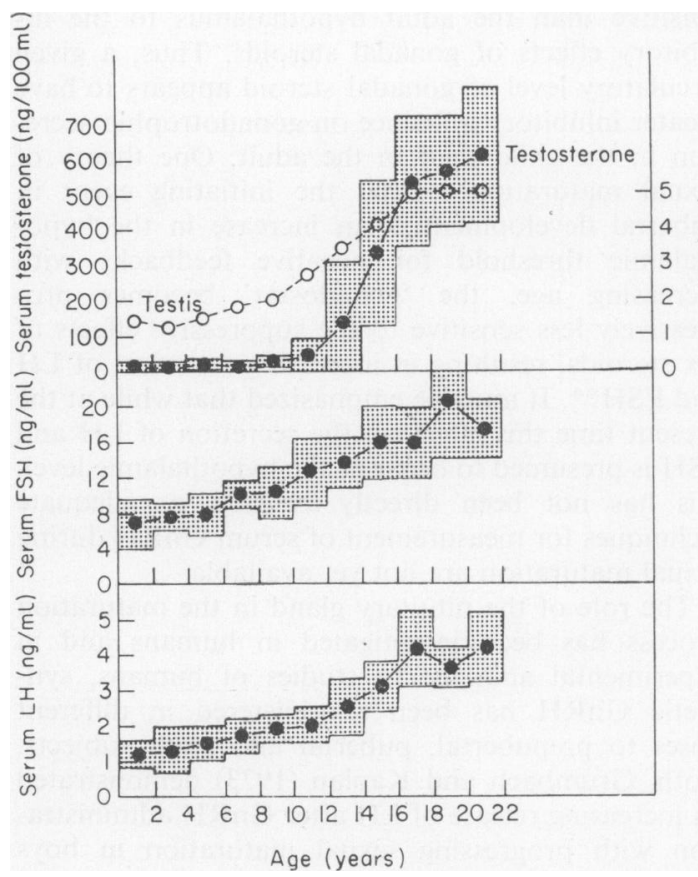

Fig. 6. Cross sectional data demonstrating the changes in test is size and serum LH, FSH, and testosterone during sexual maturation in boys (with permission, adapted from Winter and Faiman, 1972a; Faiman and Winter, 1971).

Since that time, the pattern of serum LH and FSH during sexual maturation has been published by many laboratories.

Serum FSH is now known to be present in high concentrations in the serum of the fetus, the concentrations actually decreasing as term is reached (Grumbach and Kaplan, 1973). Serum LH and FSH have been detected at birth. In one study, FSH concentrations in girls were elevated in the first 2 years of life, reached a nadir at about age 6-8 and then increased again during puberty (Faiman and Winter, 1971). Figures 6 and 7 show representative data for serum LH and FSH during sexual maturation in both sexes (Winter and Faiman, 1972a; Faiman and Winter, 1971; Jenner et al., 1972). Serum gonadotrophins rise during maturation, serum FSH levels increasing to a greater degree than $\mathrm{LH}$ in the early stages of puberty (Faiman and Winter, 1971; Jenner et al., 1972; Penny et al., 1970). In the female, serum gonadotrophin levels eventually begin to demonstrate the cyclic pattern of the adult, but this is preceded by a change from the pattern of constant secretion of the prepubertal child to the pulsatile or episodic secretion of gonadotrophins of the adult (Rubin et al., 1972; Boyar et al., 1973). The pulsatile pattern is heralded at about stage III of puberty by a

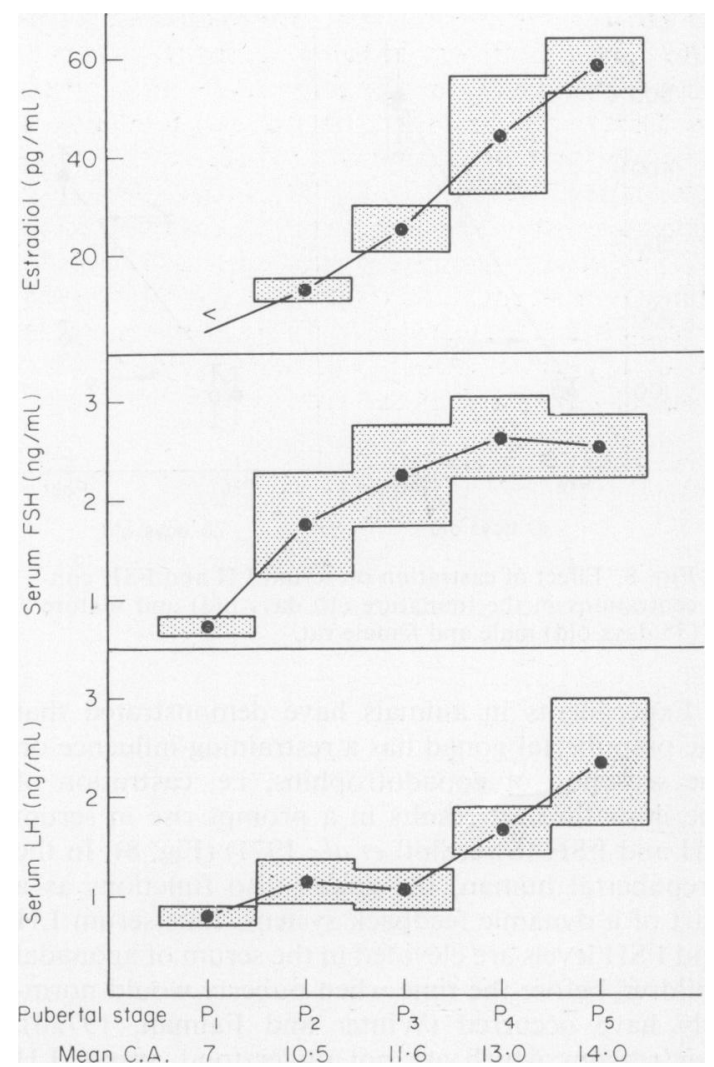

FIG. 7. Cross sectional data demonstrating the changes in serum LH, FSH and oestradiol during sexual maturation in girls (with permission, adapted from Jenner $e t$ al., 1972).

striking sleep-associated release of gonadotrophins that has not been found in either the prepubertal child or in the adult (Boyar et al., 1972).

What causes the increase in blood LH and FSH observed in children? Several possibilities exist. (1) A maturation process occurs in the hypothalamus which results in an increasing capacity to secrete GnRH and/or decreasing sensitivity to the inhibitory influences of gonadal steroids on GnRH secretion; (2) the pituitary becomes more responsive to the effects of $\mathrm{GnRH}$ and secretes increasing amounts of gonadotrophins; (3) areas of the central nervous system outside the hypothalamus mature and modify hypothalamic function resulting in the changes listed in (1) above. It is noteworthy that in female rats and cattle sexual maturation can occur without detectable increases of LH concentrations (Odell, Hescox and Kiddy, 1970; Swerdloff, Jacobs and Odell, 1972b) and that in the rat of both sexes, serum FSH actually falls during sexual maturation (Swerdloff et al., 1971; 1972b). 


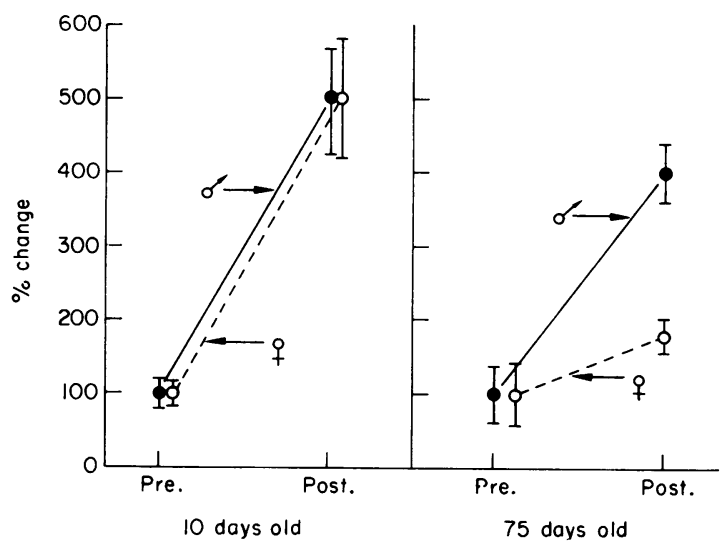

FIG. 8. Effect of castration on serum LH and FSH concentrations in the immature (10 days old) and mature ( 75 days old) male and female rat.

Experiments in animals have demonstrated that the prepubertal gonad has a restraining influence on the secretion of gonadotrophins, i.e. castration of the immature rat results in a prompt rise in serum LH and FSH (Swerdloff et al., 1971) (Fig. 8). In the prepubertal human, the gonad also functions as a part of a dynamic feedback system: thus serum LH and FSH levels are elevated in the serum of agonadal children before the time when puberty would normally have occurred (Winter and Faiman, 1972b). For reasons which are not understood, serum LH and, to a lesser degree, FSH levels in agonadal children do not reach the levels found in castrated adults until the individual attains the chronological age usually associated with normal pubertal development. That is, although serum gonadotrophins in the agonadal child are usually higher than in children of the same chronological age they increase further at about the age of 12 years. This change may be due to inherent hypothalamic maturation or due to changing pituitary sensitivity to secreted GnRH (see below). Having demonstrated that the gonads exert an inhibitory influence on the hypothalamicpituitary axis before puberty, the question arises as to why the normal immature child with low circulating gonadal steroids does not have higher serum gonadotrophins. Data have been presented in experimental animals* (Byrnes and Meyer, 1951; Ramirez and McCann, 1963) and to a limited extent in humans (Kelch, Kaplan and Grumbach, 1973) which indicates that the immature hypothalamus is more

* Most investigators believe that the immature rat is more sensitive than the mature rat to feedback suppression of gonadotrophins by gonadal steroids. In our laboratory we have consistently observed this phenomenon for FSH. In our studies the effects on sexual maturation of changing feedback sensitivity of LH in the rat remain less certain. sensitive than the adult hypothalamus to the inhibitory effects of gonadal steroids. Thus, a given circulatory level of gonadal steroid appears to have greater inhibitory influence on gonadotrophin secretion in the child than in the adult. One theory of sexual maturation is that the initiating event in pubertal development is an increase in the hypothalamic threshold for negative feedback: with increasing age, the 'gonadostat' becomes progressively less sensitive to the suppressive effects of sex steroids, resulting in increasing secretion of $\mathbf{L H}$ and FSH $^{* *}$. It must be emphasized that while at the present time this effect on the secretion of $\mathbf{L H}$ and FSH is presumed to occur at the hypothalamic level, this has not been directly assessed, as adequate techniques for measurement of serum GnRH during sexual maturation are not yet available.

The role of the pituitary gland in the maturation process has been investigated in humans and in experimental animals. In studies of humans, synthetic GnRH has been administered in different doses to prepubertal, pubertal and adult subjects. Roth, Grumbach and Kaplan (1973) demonstrated an increasing release of $\mathrm{LH}$ after GnRH administration with progressing sexual maturation in boys (Fig. 9). These data indicate that increasing GnRH levels and increasing pituitary response to GnRH

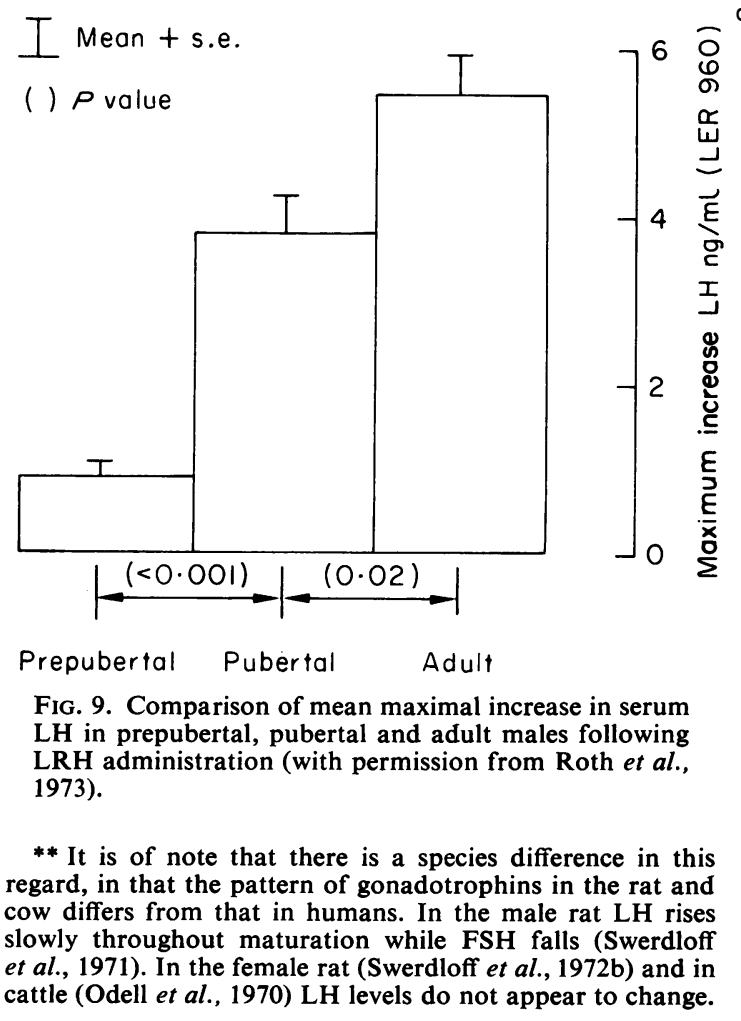


might be factors responsible for sexual maturation in boys. In contrast to the release of $\mathrm{LH}$, the increment in FSH response above baseline was not increased by age: thus, in their study and in that of Job et al. (1972), the prepubertal boy has a higher serum FSH to $\mathrm{LH}$ ratio after GnRH than does the adult.

Another aspect of the mechanism of onset of puberty in the female is the maturation of the positive or stimulatory feedback response to oestrogen that is required for the pre-ovulatory LH and FSH surge depicted in Fig. 5. Sufficient data are not available to establish whether the development of peak $\mathrm{LH}$ responses (as seen before ovulation) in the maturing female requires increased sensitivity of the hypothalamus to the stimulatory influence of oestrogen or is simply the result of gonadal steroids reaching a threshold level for positive feedback of gonadotrophin secretion. Winter and Faiman (1973) have evaluated the sequence of hormonal changes that occurred at about the time of menarche in a small group of girls. They found that oestrogen concentrations began to develop some cyclicity before menarche but they were not associated with an LH surge. Menarche actually occurred before the first ovulatory cycle and appeared to be related to fluctuating oestrogen levels. In the period following menarche, the amplitude of cyclic oestrogen elevations increased and ultimately LH surges were induced and ovulation occurred.

\section{Role of the gonad in the maturation process}

Until recently, it was generally believed that the gonad played a rather passive role in sexual maturation-that is, that hormone secretion by the gonad was entirely determined by the amount of gonadotrophic hormone it was exposed to at any particular time. Recently, evidence has been obtained that indicates that the gonad (at least in the male) also undergoes maturational changes, becoming progressively more sensitive to stimulation by gonadotrophin during pubertal development. Studies in our laboratory have demonstrated that 5 days after hypophysectomy the testis of the immature rat does not respond to administered LH (Swerdloff et al., 1972b; Odell et al., 1973). This observation, which contrasted markedly with the effects of $\mathrm{LH}$ in similarly treated adult animals, led us to suspect that the immature gonad of intact animals might also be less capable of responding to the stimulatory effects of pituitary hormones.

In subsequent studies in intact male animals, we demonstrated that immature rats secrete much less testosterone after a single dose of LH than do adults. The response progressively increased with increasing age and finally reached adult levels (Odell et al., 1974) (Fig. 10). The mechanism underlying the increasing response to $\mathrm{LH}$ is unclear but we have found that FSH administration to the previously described hypophysectomized immature rat returns LH-stimulated Leydig cell function towards normal (Odell et al., 1973). More recent studies have demonstrated that treatment of immature intact rats with FSH results in increased serum testosterone levels (reflected by increased ventral prostate weight) and significantly augments testosterone secretion in response to LH. Data in man appear to support this concept of gonadal maturation. Diminished responsiveness of the prepubertal testis to HCG has been demonstrated (Saez and Bertrand, 1968; Fraser, Gafford and Horton, 1969; Winter, Taraska and Faiman, 1972; Sizoneko, Cuendet and Paunier, 1973) with the magnitude of testosterone responses in boys increasing with age (Winter et al., 1972). While Winter et al. (1972) found the testosterone response to HCG correlated both with basal LH and FSH levels, Sizonenko et al. (1973) reported that the response to HCG correlated better with basal serum FSH concentrations.

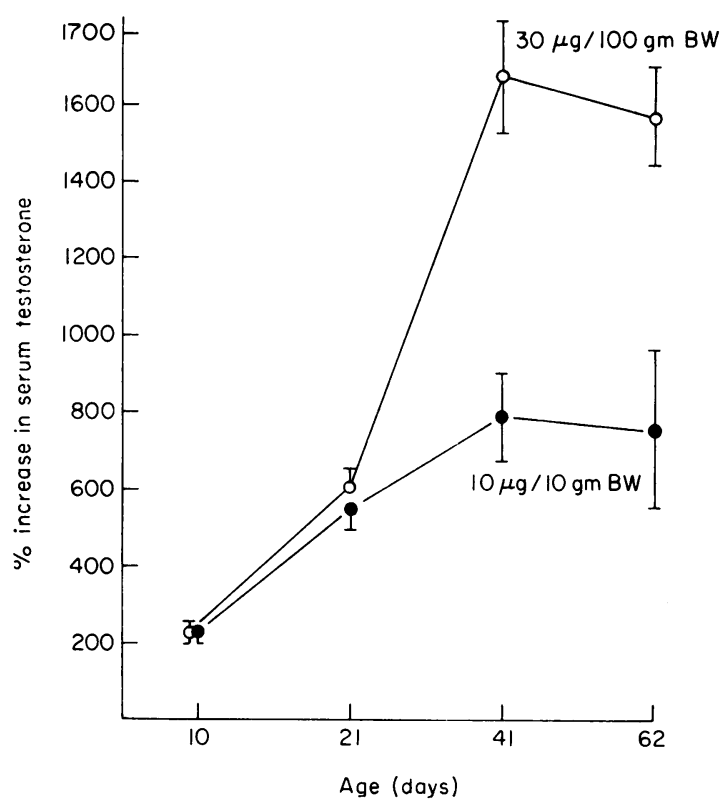

FIG. 10. Percentage increase in serum testosterone plotted against age of intact male rat for two doses of NIH-LH-B7. Note that for both doses, with increasing age, a greater change in serum testosterone occurred in response to a constant dose of $\mathrm{LH}$ (with permission from Odell et al., 1974).

The observation that in boys serum FSH levels rise earlier than $\mathrm{LH}$ and that both precede the steep increase in serum testosterone suggests that an 
TABLE 3. Hormonal events associated with sexual maturation

\begin{tabular}{|c|c|c|}
\hline \multirow[t]{2}{*}{ Hypothalamic-pituitary axis } & $\left.\begin{array}{l}\text { Reduing sensitivity of hypothalamus } \\
\text { (and pituitary ?) to negative feedback } \\
\text { by gonadal steroids } \\
\text { Increasing capacity to secrete gonado- } \\
\text { trophins (non-feedback related) } \\
\text { Pubertal sleep-induced episodic release } \\
\text { of LH } \\
\text { Development of adult pattern of episodic } \\
\text { release of gonadotrophins } \\
\text { Increasing pituitary response to GnRH }\end{array}\right\}$ & $\begin{array}{l}\text { Increasing levels of serum } \mathrm{LH} \text { and } \\
\text { FSH }\end{array}$ \\
\hline & $\begin{array}{l}\text { Development of positive feedback re- } \\
\text { sponse to gonadal steroids in females }\end{array}$ & $\begin{array}{l}\text { Cyclic preovulatory gonadotro- } \\
\text { phin surge resulting in ovula- } \\
\text { tion }\end{array}$ \\
\hline Gonads & $\left.\begin{array}{l}\text { Increasing gonadal sensitivity to gona- } \\
\text { dotrophins (in males) } \\
\text { Increasing gonadal steroid secretion } \\
\text { associated with increasing gonadotro- } \\
\text { phin levels }\end{array}\right\}$ & $\begin{array}{l}\text { Increasing serum levels of gonadal } \\
\text { steroids and adrenal androgens }\end{array}$ \\
\hline Adrenal & Increasing adrenal secretion of androgens & \\
\hline
\end{tabular}

important sequence of maturational events may be occurring. Fewer data are available on whether the ovary undergoes similar maturational changes.

\section{Adrenarche}

The development of pubic and axillary hair in the female is believed to result from increasing production of androgens, which are largely derived from adrenal precursors. During puberty, plasma dehydroepiandrosterone (DHA), dehydroepiandrosterone sulphate (DHA-S), and $\Delta^{4}$ androstenedione all increase several-fold, while plasma testosterone increases more modestly (Saez et al., 1972; Frasier and Horton, 1966; Gandy and Peterson, 1968; Forest and Migeon, 1970). Since DHA and DHA-S can be converted peripherally to androstendione (Loriaux and Noall, 1968; Drucker et al., 1972) and androstendione can be converted peripherally to testosterone (Horton and Tait, 1966), the increasing concentrations of these steroids provide a physiologic basis for the occurrence of adrenarche. Evidence for an adrenal source of these androgen precursors includes the observations that the increased plasma levels of DHA, DHA-S, and androstendione seen during sexual maturation can be suppressed by treatment with dexmethasone (Rosenfield, 1971). The secretion of these steroids can be stimulated in prepubertal children by the administration of ACTH (Rosenfield, Grossman and Ozoa, 1971). This observation suggests that the increase in serum concentrations of these steroids in the maturing child could be due either to increasing secretion of ACTH or to changing adrenal responsiveness to circulating ACTH. Increasing ACTH secretion seems an unlikely cause of adrenarche as cortisol and aldosterone secretion (when corrected for body mass) do not increase during puberty. In contrast, altered adrenal response to ACTH is suggested by the observation that the ratio of androstendione to DHA and DHA-S is different in normally maturing children from that in prepubertal children receiving exogenous ACTH (Rosenfield et al., 1971; Rosenfield, 1971). The mechanism by which this change takes place is unknown; perhaps changing enzymatic activity in the adrenal gland results in increased adrenal androgen synthesis by shuttling steroid precursors into pathways of androgen biosynthesis.

\section{Integration of maturational events}

Most of the observable manifestations of sexual maturation are due to increasing blood levels of sex steroids. The mechanisms by which the secretion of these hormones increase at the time of puberty are complex and involve maturation of the hypothalamus, pituitary, gonad and adrenal glands. These changes and their interrelationships are outlined in Table 3.

\section{References}

Abraham, G.E., Swerdloff, R.S., Tulchinsky, D. \& ODELL, W.D. (1971) Radioimmunoassay of plasma 17 hydroxyprogesterone. Journal of Clinical Endocrinology and Metabolism, 33, 42.

Boyar, R.M., Finkelstein, J.W., David, R., RoffWARg, H., Kapen, S., Weitzman, E.D. \& Hellman, L. (1973) Twenty-four hour patterns of plasma luteinizing hormone and follicle-stimulating hormone in sexual precocity. New England Journal of Medicine, 289, 282.

Boyar, R., Finkelstein, J., RofFWARd, H., KaPen, S., WeITzMAN, E. \& HellmaN, L. (1972) Synchronization of augmented luteinizing hormone secretion with sleep during puberty. New England Journal of Medicine, 287, 582.

BYRNES, W.W. \& MEYER, R.K. (1951) The inhibition of gonadotropic hormone secretion by physiological doses of estrogen. Endocrinology, 48, 133. 
Drucker, W.D., Blumberg, J.M., Gandy, H.M., DaVid, R.R. \& VERDE, A.L. (1972) Biologic activity of dehydroepinandrosterone sulfate in man. Journal of Clinical Endocrinology and Metabolism, 35, 48.

FAIMAN, C. \& WINTER, J.S.D. (1971) Sex differences in gonadotropin concentrations in infancy. Nature, 232, 130.

Forest, M.G. \& Migeon, C.J. (1970) Percentage of testosterone, androstenedione and dehydroisoandrosterone bound to plasma proteins in preadolescent children. Journal of Pediatrics, 76, 732.

Frasier, S.D., GafFord, F. \& Horton, R. (1969) Plasma androgens in childhood and adolescence. Journal of Clinical Endocrinology and Metabolism, 29, 1404.

Frasier, S.D. \& HorTon, R. (1966) Androgens in the peripheral plasma of prepubertal children and adults. Steroids, 8, 777.

FRISCH, R.E. (1972) Weight at menarche: Similarity for wellnourished and under-nourished girls at differing ages, and evidence for historical constancy. Pediatrics, 50, 445.

GaNDY, H.M. \& Peterson, R.E. (1968) Measurement of testosterone and 17-ketosteroids in plasma by the double isotope dilution derivative technique. Journal of Clinical Endocrinology and Metabolism, 28, 949.

GrumbaCh, M.M. \& KaPlan, S.M. (1973) Foetal and Neonatal Physiology, p. 462. Cambridge University Press.

HORTON, R. \& TAIT, J.F. (1966) Androstenedione production and interconversion rates measured in peripheral blood and studies on the possible site of its conversion to testosterone. Journal of Clinical Investigation, 45, 301.

JeNNER, M.R., KelCh, R.P., KaPlan, S.L. \& GRUMBaCh, M.M. (1972) Hormonal changes in puberty. IV. plasma estradiol LH, and FSH in prepubertal children, pubertal females, and in precocious puberty, premature thelarche, hypogonadism, and in a child with feminizing ovarian tumor. Journal of Clinical Endocrinology and Metabolism, $34,521$.

Job, J.C., Garnier, P.E., Chaussain, J.L. \& Milhaud, G. (1972) Elevation of serum gonadotropins ( $\mathrm{LH}$ and FSH) after releasing hormone (LH-RH) injection in normal children and in patients with disorders of puberty. Journal of Clinical Endocrinology and Metabolism, 35, 473.

Kamberi, I.A., MiCal, R.S. \& Porter, J.C. (1971) Pituitary portal vessel function of hypothalamic extract and release of LH, FSH, and prolactin. Endocrinology, 88, 1294.

KelCh, R.P., GRUMBaCh, M.M. \& KAPLAN, S.L. (1972) Gonadotropins, p. 524. John Wiley and Sons, Inc., New York.

Kelch, R.P., Kaplan, S.L. \& Grumbach, M.M. (1973) Suppression of urinary and plasma follicle-stimulating hormone by exogenous estrogens in prepubertal and pubertal children. Journal of Clinical Investigation, 52, 1122.

LoRIAUX, D.L. \& NoALl, M.W. (1968) The conversion in vivo, of dehydroepiandrosterone sulfate to testosterone and testosterone glucuronide as reflected in urinary testosterone glucuronide. Steroids, 13, 143.

MARSHALL, W.A. \& TANNER, J.M. (1969) Variations in pattern of pubertal changes in girls. Archives of Disease in Childhood, 44, 291.

MARShall, W.A. \& TANNER, J.M. (1970) Variations in pattern of pubertal changes in boys. Archives of Disease in Childhood, 45, 13.

Odell, W.D., Hescox, M.A. \& KIDDY, C.A. (1970) Gonadotropins and Ovarian Development. Proceedings of 2 nd Workshop Meetings on Chemistry and the Human Gonadotropins and Development of the Ovary in Infancy, p. 371. E. \& S. Livingstone, Edinburgh.

Odell, W.D., Ross, G.T. \& RAYFORD, D.L. (1967) Radioimmunoassay for luteinizing hormone on human plasma in serum physiological studies. Journal of Clinical Investigation, 46, 248.
Odell, W.D. \& SWeRdLOFF, R.S. (1968) Progestogen-induced luteinizing hormone and follicle stimulating hormone surge in postmenopausal women: A simulated ovulatory peak. Proceedings of the National Academy of Sciences of the United States of America, 61, 529.

OdELL, W.D. \& SWERDLOFF, R.S. (1974) The role of the gonads in sexual maturation. In: Control of the Onset of Puberty, p. 313. (Proc. Conference, Airlie, Virginia, 1972) (Ed. by M. M. Grumbach, G. D. Grave \& F. E. Mayer.) John Wyley \& Sons, New York.

Odell, W.D., Swerdloff, R.S., Bain, J., Wollesen, F. \& GROVER, P.K. (1974) The effect of sexual maturation of testicular sensitivity to $\mathrm{LH}$ stimulation of testosterone secretion in the intact rat. Endocrinology, 95, 1380.

Odell, W.D., SWerdloff, R.S., JACOBS, H.S. \& HescoX, M.A. (1973) FSH induction of sensitivity to LH: One cause of sexual maturation in the male rat. Endocrinology, 92 , 160.

Penny, R., Guyda, H.J., Baghdassarian, A., Johnason, A.J. \& BlizzARD, R.M. (1970) Correlation or serum follicle stimulating hormone (FSH) and luteinizing hormone (LH) as measured by radioimmunoassay in disorders of sexual development. Journal of Clinical Investigation, 49, 1847.

RAMIREZ, D.V. \& MCCANN, S.M. (1963) Comparison of the regulation of luteinizing hormone $(\mathrm{LH})$ secretion on immature and adult rats. Endocrinology, 72, 452.

Rifkind, A.B., Kulin, H.E. \& Ross, G.T. (1967) Follicle stimulating hormone (FSH) and luteinizing hormone (LH) in the urine of prepubertal children. Journal of Clinical Investigation, 46, 1925.

Root, A.W. (1973) Endocrinology of puberty. Journal of Pediatrics, 83, 1.

Rosenfield, R.L. (1971) Plasma 17-ketosteroids and 17-beta hydroxysteroids in girls with premature development of sexual hair. Journal of Pediatrics, 79, 260.

Rosenfield, R.L., Grossman, B.J. \& OzOA, N. (1971) Plasma 17-ketosteroids and testosterone in prepubertal children before and after ACTH administration. Journal of Clinical Endocrinology and Metabolism, 33, 249.

Roth, J.C., GrumbaCH, M.M. \& KaPlaN, S.L. (1973) Effect of synthetic luteinizing hormone-releasing factor on serum testosterone and gonadotropins in prepubertal, pubertal, and adult males. Journal of Clinical Endocrinology and Metabolism, 37, 680 .

Rubin, R.T., Kales, A., Adler, R., Fagan, T. \& Odell, W.D. (1972) Gonadotropin secretion during sleep in normal man. Science, 175, 196.

SAEZ, J.M. \& BerTrand, J. (1968) Studies of testicular function in children. Plasma concentrations of testosterone dehydroepiandrosterone and its sulfate before and after stimulation with human chorionic gonadotropin. Steroids, 12, 749.

Saez, J.M., Morera, A.M. \& Bertrand, J. (1972) Plasma concentrations of estrone $\left(E_{1}\right)$ before puberty in humans. International Congress of Endocrinology, Washington, D.C.

Schally, A.V., Kastin, A.J. \& Arimura, A. (1971) Hypothalamic follicle-stimulating hormone (FSH) and luteinizing hormone (LH) regulating hormone: Structure, physiology, and clinical studies. Fertility and Sterility, 22, 703.

Sizonenko, P.C., Cuendet, A. \& Paunier, L. (1973) FSH. I. Evidence for its mediating role on testosterone secretion in cryptorchidism. Journal of Clinical Endocrinology and Metabolism, 37, 68.

Smith, E.R. \& DAVIDSON, J.M. (1967) Differential responses to hypothalamic testosterone in relation to male puberty. American Journal of Physiology, 212, 1385.

SWerdloff, R.S., Grover, P.K., JACOBS, H.S. \& BAIN, J. (1973) Search for a substance which selectively inhibits FSH-effects of steroids and prostaglandins on serum FSH and LH levels. Steroids, 21, 703. 
SWERDLOFF, R.S., JACOBS, H.S. \& ODELL, W.D. (1972a) Synergistic role of progestogens on estrogen induction of LH and FSH surge. Endocrinology, 90, 1529.

SWERDLOFF, R.S., JACOBS, H.S. \& ODELL, W.D. (1972b) Hypothalamic-pituitary-gonadal relationships in the rat during sexual maturation. In: Gonadotropins (Ed. by B. B. Saxena, C. G. Beiling and H. M. Gandy), p. 546. John Wiley \& Sons, Inc., New York.

SWERdLOFF, R.S. \& OdELl, W.D. (1969) Serum luteinizing and follicle stimulating hormone levels during sequential and nonsequential contraceptive treatment of eugonadal women. Journal of Clinical Endocrinology and Metabolism, 29, 157.

SWERDlOFF, R.S., WALSH, P.C., JACOBS, H.S. \& OdELl, W.D. (1971) Serum LH and FSH during sexual maturation in the male rat: Effect of castration and cryptorchidism. Endocrinology, 88, 120.

TANNER, J.M. (1962) Growth at Adolescence. Blackwell Scientific Publications, Oxford.

WALSH, P.C., SWERDLOFF, R.S. \& Odell, W.D. (1973a) Feedback control of FSH in the male: Role of estrogen. Acta endocrinologica, 74, 449.

W AlSH, P.C., SWERdLOFF, R.S. \& OdelL, W.D. (1973b) Feed- back regulation of gonadotropin secretion in men. Journal of Urology, 110, 84.

Winter, J.S.D. \& FAIMAN, C. (1972a) Pituitary gonadal relations in male children and adolescents. Pediatric Research, 6, 126.

WinTER, J.S.D. \& FAIMAN, C. (1972b) Serum gonadotropin concentration in agonadal children and adults. Journal of Clinical Endocrinology and Metabolism, 34, 561.

WINTER, J.S.D. \& FAIMAN, C. (1973) The development of cyclic pituitary-gonadal function in adolescent females. Journal of Clinical Endocrinology and Metabolism, 37, 714.

Winter, J.S.D., Taraska, S. \& Faiman, C. (1972) The hormonal response to $\mathrm{HCG}$ stimulation in male children and adolescents. Journal of Clinical Endocrinology and Metabolism, 34, 348.

Wollesen, F., Swerdloff, R.S., Peterson, M. \& Odell, W.D. (1974) Testosterone (T) modulation of pituitary response to LRH: Differential effects on LH and FSH. Clinical Research, 22, 119A.

YEN, S.S.C. (1971) The biaphasic pattern in the feedback action of ethinyl estradiol on the release of pituitary FSH and LH. Journal of Clinical Endocrinology and Metabolism, 33, 71. 